\title{
COMPARISON AND SIMULATION STUDY OF CYLINDRICAL GAA NWMBCFET FOR SUB 35NM
}

\section{S. Ashok Kumar}

Research Scholar, Centre for VLSI Design, Department of Electronics and Communication Engineering, Kalasalingam Academy of Research and Education, Virudhunagar, (India).

E-mail:6691ashok@gmail.com ORCID: http:// orcid.org/0000-0002-0957-6685

\section{J. Charles Pravin}

Associate Professor, Centre for VLSI Design, Department of Electronics and Communication Engineering, Kalasalingam Academy of Research and Education. Virudhunagar, (India).

\section{Citación sugerida:}

Kumar, S. A., y Pravin, J. G. (2021). Comparison and Simulation study of Cylindrical GAA NWMBCFET for sub 35nm. 3C Tecnología. Glosas de innovación aplicadas a la pyme, Edición Especial, (noviembre, 2021), 199-209. https://doi.org/10.17993/3ctecno.2021.specialissue8.199-209 


\section{ABSTRACT}

In this paper, a cylindrical Gate All Around Nano Wire Field Effect Transistor (GAA NWFET) is compared with cylindrical Gate All Around Nano Wire Multi Bridge Channel Field Effect Transistor (GAA NWMBCFET) for sub 35nm devices using Technology Computer Aided Design (TCAD) simulation tool. Instead of one channel with equal distance in vertical and horizontal stacking, about 12 thin channels have been created in GAA NWMBCFET. The device performance has been numerically evaluated using coupled Drift-diffusion (DD) method and Shockley-Read-Hall Recombination method (SRH). The compared transfer and output characteristics of GAA NWFET and GAA NWMBCFET has been reported using the TCAD numerical simulation calibrations. The inclusion of multi bridge channel in the device has increased its current drive because of the Ultra-Thin Body (UTB). It has been accounted for that the GAA structure has a decent insusceptibility to short channel impacts.

\section{KEYWORDS}

Cylindrical GAA NWFET, Cylindrical GAA NWMBCFET, TCAD, UTB, MBCFET. 


\section{INTRODUCTION}

Gate All Around structure is a promising candidate for short channel transistors as per ITRS 2015 (ITRS version 2.0., 2015). The idea of Multi Bridge channel originates from stacking channels one over the other. Contingent upon the quantity of channels stacked in the transistor MBCFET ensures high output current. The output current is increased by using Ultra-Thin Body (UTB) in the Si channel and also by reducing the oxide thickness (Lee et al., 2003; Lee et al., 2004a).

GAA NWFET is one of the better alternatives for accomplishing superiority in Nano-level transistors. The GAA NWFET could decrease short channel impacts like Drain Induced Barrier Lowering (DIBL), SS and VTH roll off because of its geometric structure (Singh $e t$ al., 2006; Al-Ameri et al., 2017). The GAA NWFET constitutes of various structures like cubical, cylindrical and elliptical (Lin et al., 2018; Nagy et al., 2018; Salmani-Jelodar et al., 2015). An MBCFET of $5 \mu \mathrm{m}$ channel length was fabricated in the year 2003, and achieved high output current of 4.6 times larger (Lee et al., 2003). In Lee et al. (2004a) an MBCFET structure in 2004 with a reduced gate length of $250 \mathrm{~nm}$ was manufactured. Multi-channel transistors were fabricated with different materials having gate lengths of $90 \mathrm{~nm}$ and $30 \mathrm{~nm}$ as discussed in Lee et al. (2004b) and Yoon et al. (2004) respectively. All multi bridge channel devices with enlarged width attained high output current as given in Yoon et al. (2004); Lee et al. (2003); Lee et al. (2004b). An n-channel cylindrical structure as like in Nayak et al. (2014), has been developed in this paper, 12 thin channels have been made rather than one channel and every channel is encompassed by an oxide layer in TCAD.

\section{DEVICE STRUCTURE}

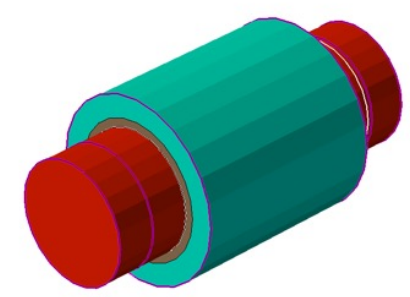

Figure 1. Cylindrical Structure formed in TCAD.

Source: own elaboration. 
The cylindrical n-channel GAA NWFET (Figure 1) is formed in TCAD by using the details given in Nayak et al. (2014), which is detailed in Table 1. The simulation was done utilizing the Drift-Diffusion and Shockley-Read-Hall models.

\section{A. Drift-Diffusion Model}

In drift-diffusion model, the electron current density is:

$$
\overrightarrow{J_{n}}=\mu_{n}\left(n \nabla E_{C}-1.5 n k T \nabla \ln m_{n}\right)+D_{n}\left(\nabla_{n}-n \nabla \ln \gamma_{n}\right)
$$

and the current density of holes is given by:

$$
\overrightarrow{J_{p}}=\mu_{p}\left(p \nabla E_{v}-1.5 p k T \nabla \ln m_{p}\right)+D_{p}\left(\nabla_{p}-n \nabla \ln \gamma_{p}\right)
$$

The first term takes into account the contribution due to the spatial variations of the electrostatic potential, the electron affinity, and the band gap. The remaining terms consider the contribution due to the gradient of concentration, and the spatial variation of the effective masses mn and mp. Through the Einstein relation the diffusivities are derived using the mobilities.

$$
D_{n}=k T \mu_{n} \text { and } D_{p}=k T \mu_{p}
$$

Table 1. Parameters and values.

\begin{tabular}{|c|c|}
\hline Parameters & Values $\left(\mathbf{n m} / \mathbf{c m}^{\mathbf{3}}\right)$ \\
\hline Gate Length & 35 \\
\hline Gate Oxide & 1.5 \\
\hline NW Diameter & 21.45 \\
\hline Drain/Source Doping & $1 \mathrm{e} 20$ \\
\hline Channel Doping & $1 \mathrm{e} 15$ \\
\hline
\end{tabular}

Source: own elaboration. 


\section{B. Shockley-Read-Hall Recombination}

Recombination through deep defect levels in the gap is usually labeled SRH recombination. In Sentaurus device, the following form is implemented:

$$
R_{n e t}^{S R H}=\frac{n p-n_{i, e f f}^{2}}{\tau_{p}\left(n+n_{1}\right)+\tau_{n}\left(p+p_{1}\right)}
$$

with:

$$
n_{1}=n_{i, e f f} \exp \left(\frac{E_{\text {trap }}}{K T}\right)
$$

and:

$$
p_{1}=n_{i, e f f} \exp \left(\frac{-E_{\text {trap }}}{K T}\right)
$$

where $E_{\text {trap }}$ is the difference between the defect level and the intrinsic level. The variable $E_{\text {trap }}$ is accessible in the parameter file. The default $E_{\text {trap }}$ value for Silicon is 0.

The doping dependence of the SRH lifetimes is modeled in Sentaurus device by use of the Scharfetter relation:

$$
\tau_{d o p}\left(N_{A, 0}+N_{D, 0}\right)=\tau_{d o p}+\frac{\tau_{\max }-\tau_{\min }}{1+\left(\frac{N_{A, 0+} N_{D, 0}}{N_{r e f}}\right)^{\gamma}}
$$

After achieving same IV characteristics with (Nayak et al., 2014) 12 channels have been formed in the place of single channel and the IV characteristics are measured using the same models. The primary objective here is to increase the output current drivability of the device without increasing the width of the transistor. The schematic of the Multi Bridge channels in a cylindrical channel have been demonstrated in Figure 2b, 2c. The Figure 2d shows equal distance being given to 12 channels and the electrostatic integrity has also been maintained.

The splitted 12 thin channels are surrounded by an oxide layer. A direct metal contact on oxide layer was given with the work function of 4.461 and a high $\mathrm{k}$ dielectric is used as an oxide to control the Ioff value. 


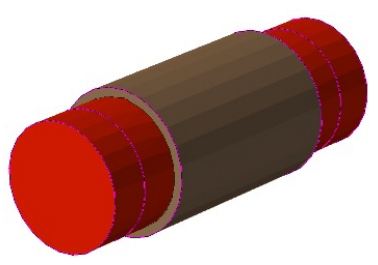

(a)

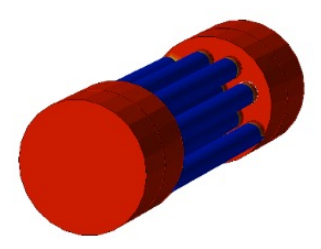

(b)

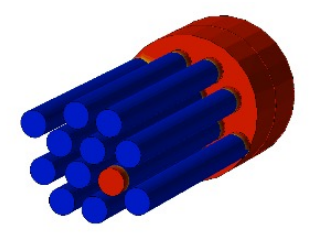

(c)

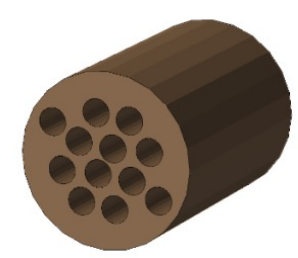

(c)

Figure 2. a) Cylindrical Structure with oxide layer, b) Multi Bridge Channel, c) 12 Channels, d) Oxide layer surrounding channels.

Source: own elaboration.

\section{RESULTS}

Figures 3 and 4 shows the comparison between the transfer and output characteristics of cylindrical GAA NWFET and cylindrical GAA NWMBCFET which clearly indicates that the Multi Bridge increases the current drivability and the short channel effects like Drain 
Induced Barrier Lowering (DIBL) and SS are reduced due to the surrounding oxide layer. The current drive of the device was increased due to the presence of UTB Si channel, without having to increase the width of the transistor. In transfer characteristics the curve has been plotted for $\mathrm{V}_{\mathrm{D}}=\mathrm{V}_{\mathrm{G}}=1 \mathrm{~V}$ and $\mathrm{V}_{\mathrm{G}}=50 \mathrm{mV}, \mathrm{V}_{\mathrm{D}}=1 \mathrm{~V}$ for both cylindrical GAA NWFET and cylindrical GAA NWMBCFET. Figure 3 clearly shows an increase in current drive of the GAA NWMBCFET when compared with GAA NWMBCFET. The channel current can be increased further by reducing the oxide layer thickness but there occurs an increase in a short channel effect Threshold voltage rolloff $\left(\mathrm{V}_{\mathrm{TH}}\right.$ rolloff).

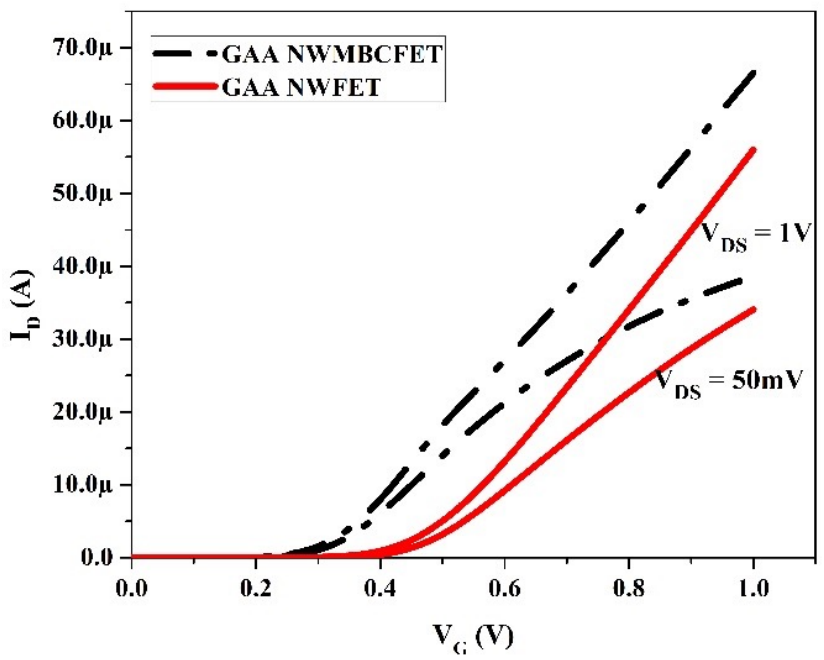

Figure 3. Compared Transfer Characteristics between GAA NWMBCFET and GAA NWFET. Source: own elaboration.

The output characteristics are plotted by varying $\mathrm{V}_{\mathrm{GS}}$ from $0.7 \mathrm{~V}$ to $0.9 \mathrm{~V}$ for both devices. By comparing the output characteristics with the GAA NWFET, the GAA NWMBCFET clearly indicates more output current. The gate effect has been spread equivalently to all the channels due to the presence of UTB and GAA, but it is still believed that the effect of electro static potential will be more in outer channels than the inner channels. In Basic GAA structure gate controls over the channels so the short channel effects will reduce but in the case 12 channels, the inner channels not directly having contact with metal gate. That may build the short channel impacts. 


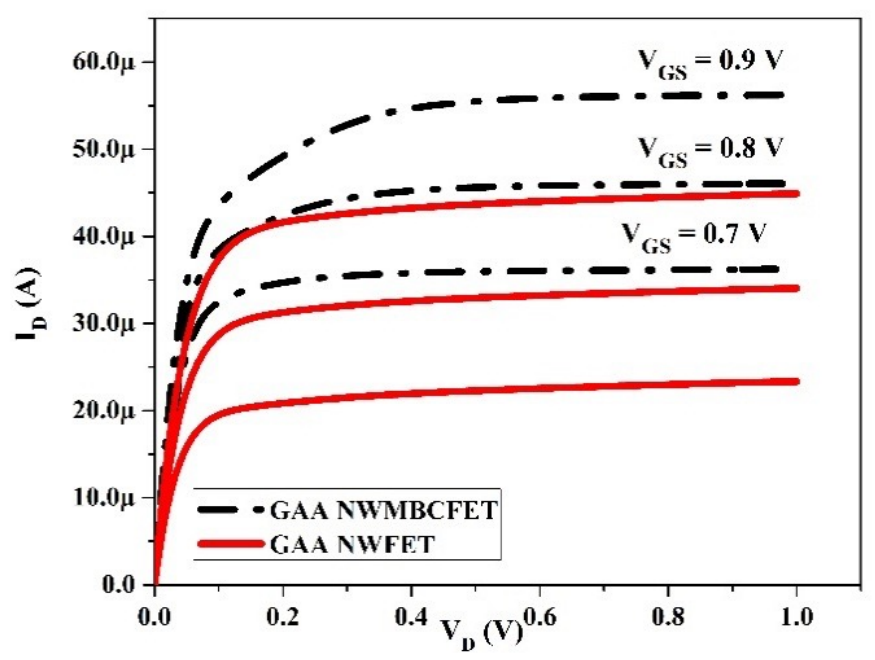

Figure 4. Compared Output Characteristics between GAA NWMBCFET and GAA NWFET. Source: own elaboration.

\section{CONCLUSIONS}

A GAA NWFET has been formed in TCAD with a gate length of $35 \mathrm{~nm}$. This device is then developed into a Nanowire Multi-Bridge-Channel FET (GAA NWMBCFET) by splitting 12 different channels from the single channel, and stacking them in vertical and horizontal manner for a gate length of $35 \mathrm{~nm}$. The incorporation of Multi Bridge channels showed an increase in current drive as compared to the normal nanowire structures. Device performance will be varied depending upon the nanowire structure too. The proposed MBC device displayed a maximum current drive of $65 \mu \mathrm{A}$, nearly $20 \%$ higher than the conventional NWFET. By isolating the channel regions from the metal gate, by using 12 channels, the MBC structure was able to impact and alter short channel effects in such devices. Multi bridge channels are believed to deliver exceptional performances for short channel devices in the future and will be a potential candidate for low power applications.

\section{ACKNOWLEDGEMENT}

The Authors are thankful to the management of Kalasalingam Academy of Research and Education (KARE) for the provision of TCAD laboratory facilities during this research. 


\section{REFERENCES}

Al-Ameri, T., Georgiev, V.P., Sadi, T., Wang, Y., Adamu-Lema, F., Wang, X., Amoroso, S.M., Towie, E., Brown, A., \& Asenov, A. (2017). Impact of quantum confinement on transport and the electrostatic driven performance of silicon nanowire transistors at the scaling limit. Solid-State Electronics, 129, 73-80. https:/ / doi. org/10.1016/j.sse.2016.12.015

Bangsaruntip, S., Gohen, G.M., Majumdar, A., Zhang, Y., Engelmann, S.U., Fuller, N.C.M., Gignac, L.M., Mittal, S., Newbury, J.S., Guillorn, M., \& Barwicz, T. (2009). High performance and highly uniform gate-all-around silicon nanowire MOSFETs with wire size dependent scaling. IEEE International Electron Devices Meeting, 1-4. https://doi.org/10.1109/IEDM.2009.5424364

ITRS version 2.0. (2015). http://www.semiconductors.org/main/2015_international_ technology_roadmap_for_semiconductors_itrs/

Lee, S.Y., Kim, S.M., Yoon, E.J., Oh, C.W., Chung, I., Park, D., \& Kim, K. (2003). A novel multibridge-channel MOSFET (MBCFET): fabrication technologies and characteristics. IEEE Transactions on Nanotechnology, 2(4), 253-257. https://doi. org/10.1109/TNANO.2003.820777

Lee, S.Y., Kim, S.M., Yoon, E.J., Oh, C.W., Chung, I., Park, D., \& Kim, K., (2004a). Three-dimensional MBCFET as an ultimate transistor. IEEE Electron Device Letters, 25(4), 217-219. https://doi.org/10.1109/LED.2004.825199

Lee, S.Y., Yoon, E.J., Kim, S.M., Oh, C.W., Li, M., Kim, D.W., Chung, I., Park, D., \& Kim, K. (2004b). Three-dimensional multi-bridge-channel MOSFET (MBCFET) fabricated on bulk Si-substrate. Conference Digest [Includes' Late News Papers' volume] Device Research Conference, 2004. 62nd DRC, 119-120. https://doi.org/10.1109/ DRC.2004.1367812

Lin, Y.R., Yang, Y.Y., Lin, Y.H., Kurniawan, E.D., Yeh, M.S., Ghen, L.G., \& Wu, Y.C. (2018). Performance of Stacked Nanosheets Gate-All-Around and Multi- 
Gate Thin-Film-Transistors. IEEE Journal of the Electron Devices Society, 6, 1187-1191. https://doi.org/10.1109/JEDS.2018.2873008

Nagy, D., Indalecio, G., García-Loureiro, A.J., Elmessary, M.A., Kalna, K., \& Seoane, N. (2018). FinFET versus gate-all-around nanowire FET: Performance, scaling, and variability. IEEE Journal of the Electron Devices Society, 6, 332-340. https:/ / doi.org/10.1109/JEDS.2018.2804383

Nayak, K., Bajaj, M., Konar, A., Oldiges, P.J., Natori, K., Iwai, H., Murali, K.V., \& Rao, V.R. (2014). CMOS logic device and circuit performance of Si gate all around nanowire MOSFET. IEEE Transactions on Electron Devices, 61(9), 3066-3074. https:/ / doi.org/10.1109/TED.2014.2335192

Salmani-Jelodar, M., Mehrotra, S.R., Ilatikhameneh, H., \& Klimeck, G. (2015). Design guidelines for sub-12 nm nanowire MOSFETs. IEEE Transactions on Nanotechnology, 14(2), 210-213. https://doi.org/10.1109/TNANO.2015.2395441

Singh, N., Agarwal, A., Bera, L.K., Liow, T.Y., Yang, R., Rustagi, S.C., Tung, C.H., Kumar, R., Lo, G.Q., Balasubramanian, N., \& Kwong, D.L. (2006). Highperformance fully depleted silicon nanowire (diameter/spl les/5 nm) gate-all-around GMOS devices. IEEE Electron Device Letters, 27(5), 383-386. https: / / doi.org/ 10.1109/ LED.2006.873381

Yoon, E.J., Lee, S.Y., Kim, S.M., Kim, M.S., Kim, S.H., Ming, L., Suk, S., Yeo, K., Oh, G.W., Choe, J.D., \& Choi, D. (2004). Sub 30 nm multi-bridge-channel MOSFET (MBCFET) with metal gate electrode for ultra high performance application. IEDM Technical Digest. IEEE International Electron Devices Meeting, 627-630. https://doi.org/10.1109/IEDM.2004.1419244 
